\title{
DESIGN, ANALYSIS AND FABRICATION OF QUADCOPTER
}

\author{
Prof.A.V. Javir ${ }^{1 *}$, Ketan Pawar ${ }^{2}$, Santosh Dhudum ${ }^{3}$, Nitin Patale ${ }^{4}$, Sushant Patil ${ }^{5}$ \\ ${ }^{1}$ Assistant Professor in Mechanical Engineering Department of Rajendra Mane college of Engineering And \\ Technology, Ambav (Ratnagiri) Mumbai University, India \\ 2,3,4 \&5 Student in Mechanical Engineering Department of Rajendra Mane college of Engineering And Technology, \\ Ambav (Ratnagiri) Mumbai University, India \\ *1arun.javir@gmail.com, ${ }^{2}$ ketanpawar219@gmail.com, ${ }^{3}$ santoshdhudum22@gmail.com, ${ }^{4}$ patlenitin7799@gmail.com, \\ ${ }^{5}$ patilsushant553@yahoo.com.
}

*Corresponding Author: -

Email: arun.javir@gmail.com

\begin{abstract}
: -
Quadcopter also known as quadrotor is the next form of helicopters having more dynamic stability than helicopters. They play a predominant role in different areas like surveillance, military operations, fire sensing and some important areas having many complexities. This paper focuses on the aerodynamic effects of quadcopter. It addresses all the aspects of quadcopter ranging from mechanical design to electronics used. It provides backup to the selection of different components with the help of various formulas from research papers. It also gives clear results with respect to weight of components and their corresponding costs. Along with this, finite element analysis is done on the frame so as to sustain the loads generated in the vehicle and concluded that small deformation occurred on the center plates are safe and within the limit.
\end{abstract}

Keywords: - "Quadrotor, Aerodynamics, Electronics, Finite Element Analysis, Frame etc."

\section{(c) $(\$)$}




\section{INTRODUCTION}

Quadcopters also known as quadrotors or multirotor aircrafts are emerging favorites in unmanned aerial vehicle (UAV) design. This is due to their ability to hover in congested areas and vertical takeoff and landing (VTOL) capability Quadcopter consist of four rotors which are fixed at the end of the frame structure. In this case, a pair of rotors along the arms of the frame rotates in clockwise direction while the remaining pair of rotors rotates in anticlockwise direction. Due to this, the resultant torque acting on the air frame structure is zero. Each rotor is connected to fixed pitch propellers. The basic idea of a quadcopter is shown in following figure.

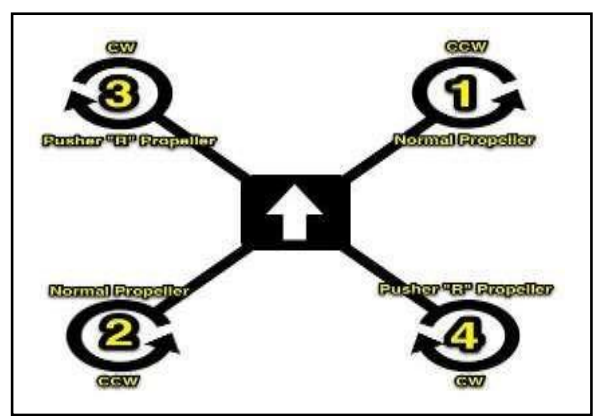

Fig.1. schematic diagram of quadcopter

\section{Content}

\section{A. Problem definition}

There are several problems faced in existing systems, particularly in the field of transportation which are listed as follows-

1) Costly:To deliver parcels from one place to other leads to increased fuel consumption and this thereby increases air pollution and expenditure.

2) Large amount of man-power:Transportation of goods is not limited to a particular area so, large number of skilled manpower is required for transporting parcels.

3) Topographical limitations:Topographical aspects may vary from place to place thus putting additional burden on human skills.

4) Human Endangerment:Emotions such as fear, nervousness and tension can lead to wrong decision which may result in fatal consequence.

\section{B. Objectives}

1) To study quadcopter flight dynamics.

2) To determine a suitable quadcopter RC UAV design.

\section{Quadcopter flight dynamics}

Quadcopter operates within two frames of reference. First is its own frame of reference which is termed as body frame whereas the second is measured relative to world frame of reference which is termed as inertial frame. In case of body frame, the rotor axes are pointing in positive $\mathrm{z}$ direction with the arms pointing in $\mathrm{x}$ and $\mathrm{y}$ directions (Fig 2) while in case of inertial frame, the gravity pointing in the negative $\mathrm{z}$ direction (Fig 3 ).

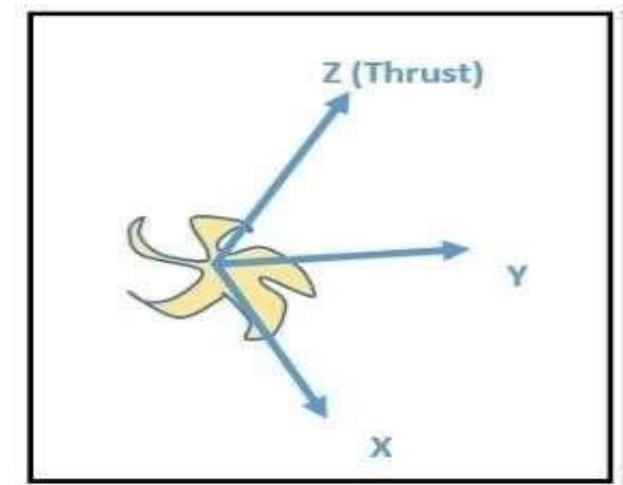

Fig. 2. Body frame

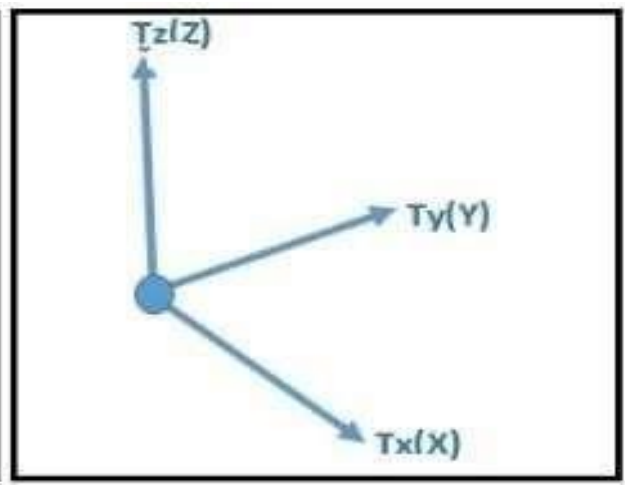

Fig.3. Inertial frame

Quadcopter is lifted up high in the air with the help of propellers. These propellers convert rotational motion into thrust and this can be explained with the help of Bernoulli's principle and Newton's third

law. Every action has equal and opposite reaction. 


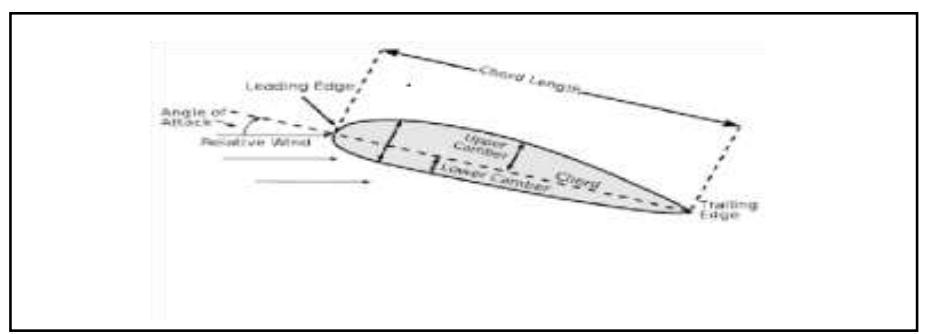

Fig.4 . Air foil

1) Bernoulli's principle: Bernoulli's principle states that for an inviscid flow of no conducting fluid, and increase in the speed of fluid occurs simultaneously with a decrease in pressure or a decrease in the fluid's potential energy.

2) Newton's third law:An air foil is the shape of the wing or blade as seen in the cross section, when moved through a fluid produces an aerodynamic force. Due to airfoil shape of the propeller, the air moves faster over the top than under the bottom which results in a greater pressure difference below the airfoil than above it. This pressure difference in turn produces the required thrust.

\section{Thrust Calculations}

The force normal to the propellers required for providing motion to the Quadcopter is termed as thrust. This force is generated with the help of rotors which spin at a certain angular velocity. In general, the thrust generated by a particular rotor is,

Where, $\rho=$ real time air density of air $(\mathrm{Kg} / \mathrm{m} 3)$

$$
\mathrm{T}=\rho \mathrm{AVr}^{2}
$$

$\mathrm{A}=$ Cross sectional area of the propellers.

$\mathrm{Vr}=$ Instantaneous peripheral velocity of rotors

$(\mathrm{r}=1,2,3 \ldots)=\mathrm{r}^{*} \mathrm{w}(\mathrm{m} / \mathrm{s})$

\section{E. Take-off and Landing mode}

During takeoff mode, the quadcopter undergoes a translational motion about the positive $\mathrm{z}$ axis of inertial frame whereas during the landing mode, the quadcopter undergoes a translational motion about the negative $\mathrm{z}$ axis of inertial frame. This is done with the help of throttle given via radio transmitter in which the microcontroller automatically increases or decreases the speed of rotors in such a way that the motion occurs only along the $\mathrm{z}$ axis of the inertial frame. The thrust generated in this case is given by,

$$
\text { Net T }=\rho A \sum_{r=1}^{2} V r^{2}-\rho A \sum_{r=3}^{4} V r^{2}
$$

\section{$F$. Hovering}

Hovering is termed as the state of constant altitude maintained by quadcopter. This is possible only when the net thrust exerted on the frame of quadcopter is zero. For the net thrust to be equal to zero, the pair of rotors along $\mathrm{x}$ axis should spin at equal speed and opposite direction with respect to the pair of rotors along y axis.

From above equation, Net $\mathrm{T}=0$

$$
\rho A \sum_{r=1}^{2} V r^{2}=\rho A \sum_{r=1}^{2} V r^{2}
$$

It is important to note that net tangential acceleration in take off, landing and hovering mode is zero which restricts its translational motion along $\mathrm{x}$ and $\mathrm{y}$ axes respectively.

\section{G. Quadcopter electronic components}

1) Motors: Brushless DC motors also termed as BLDC motors are used in Quadcopters. Thesemotors consist of a permanent magnet which rotates around a fixed armature. They offer several advantages over brushed DC motors which include more torque per weight, reduced noise, increased reliability, longer life time and increased efficiency. 


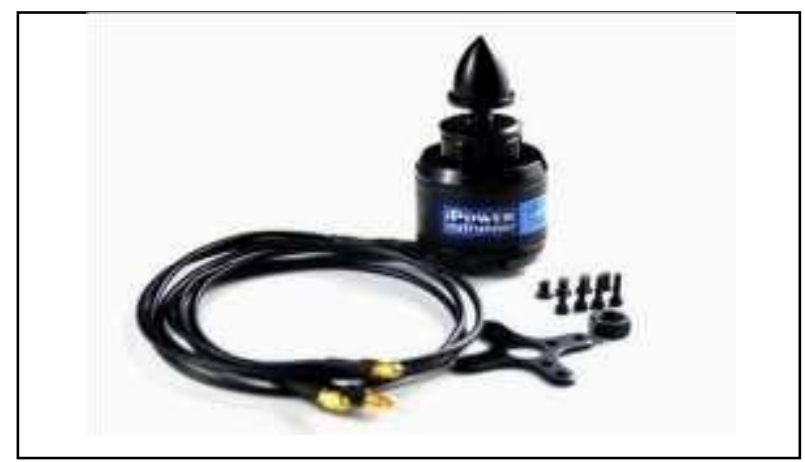

Fig.5.Brushless Motors

Motor calculations: The motors should be selected in such a way that it follows following thrust to weight relationship. Ratio $=$ Thrust $/$ weight $=\mathrm{ma} / \mathrm{mg}=\mathrm{a} / \mathrm{g}$

Thus, vertical takeoff and vertical landing (VTOL) is possible only when,(a / g) $>1$ or in other words, The total thrust to total weight ratio should be greater than 1 so that the quadcopter can accelerate in the upward direction. In this case, we assumed that,

$$
\begin{aligned}
& \text { Total Thrust }=2 *(\text { Total weight of Quadcopter }) \\
& \text { Thrust provided by each motor }=\frac{\text { Total Thrust }}{4}
\end{aligned}
$$

2) Propellers: Propeller is a type of fan that converts rotational motion into thrust. Generally, propellers are classified on the basis of their diameter and pitch and are represented in terms of product of diameter and pitch. For e.g. $10 * 4.7$, $10 * 4.5$, etc. The diameter of propeller indicates the virtual circle that the prop generates whereas the pitch indicates the amount of travel per single rotation of propeller. In order to counter motor torque, Quadcopter require two clockwise and two anticlockwise rotating propellers.

All the propellers used in quadcopter should have same diameter and pitch. Many motors come with propeller specifications so as to have optimum power consumption. If propeller specifications are not mentioned on motor then we have to use trial and error method.

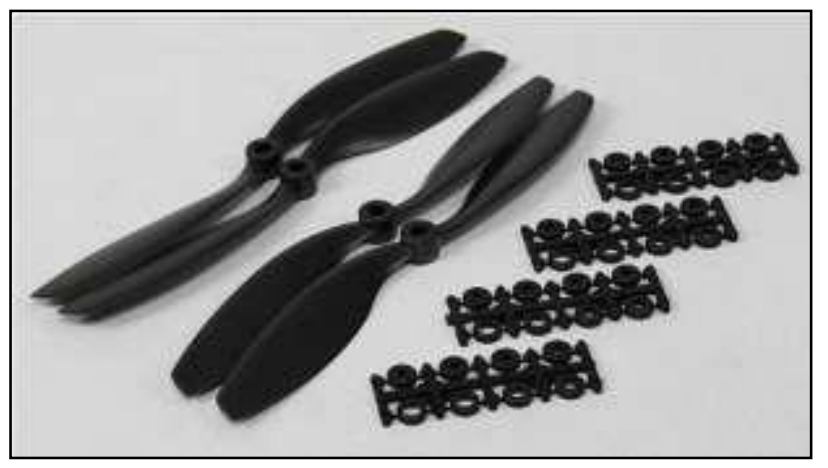

Fig.6. Propellers

3) Electronic speed controllers: Low voltage and current is provided by the microcontroller andthis is not sufficient to drive motors. To drive the motors at specific speed, we require a motor driver to supply specific amount of voltage and current required by them and this work is done by electronic speed controller.

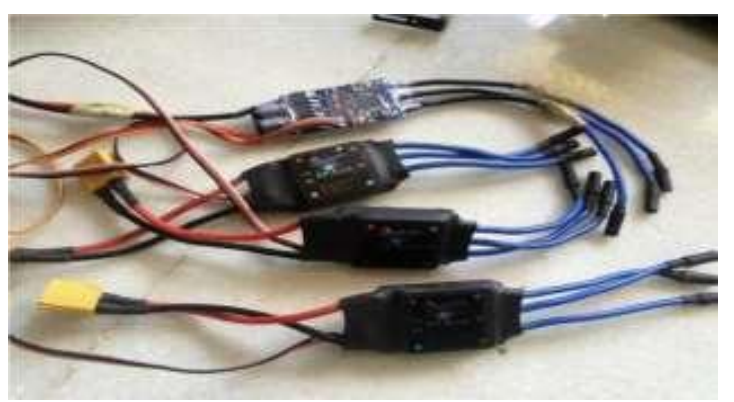

Fig.7 . Electronic speed controller 


\section{ESC calculations}

\section{ESC rating $=[1.2 \text { to } 1.5]^{*}$ (max. ampere rating of motor $)$}

Battery: Lithium Polymer (Li-Po) batteries are used in quadcopter. These batteries are rechargeable and also have low weight and high voltage capacity as compared to other type of batteries. Battery chargers are required for charging the battery

\section{Battery calculations}

Max. Current withdrawal by motors=no. of motors * maximum current withdrawal by single motor $=4 * 15$

$=60 \mathrm{~A}$

The discharge current of battery should be higher than the maximum current withdrawn by motors.

Where, discharge current $=$ Capacity in ampere $*$ discharge rate.

If we assume a constant current draw of $20 \mathrm{~A}$, then flight time for quadcopter is calculated as follows,

$$
\text { Flight time }=(\text { Capacity in amperes/Current draw }) * 60
$$

5) Flight controller: To maintain balance, the quadcopter should continuously take measurements from the sensors and make adjustment accordingly to the speed of the rotors to keep the body level. Flying capabilities and cost are the two main factors to be considered while selecting flight controller.

Flying capabilities consists of following basic factors-

$>$ Gyro stabilization: It is the ability to keep the copter stable and level under the pilot control.

Self-leveling: It is the ability to automatically adjust itself during any orientation so that the copter stays level.

Altitude hold: It is the ability to hover at a certain distance from ground without having to manually adjust the throttle.

6) Transmitter and receiver: The Transmitter ( $\mathrm{Tx})$ and Receiver ( $\mathrm{Rx})$ system allows the Quadcopter to be remotely controlled through a wireless signal. The aircraft controls would typically include throttle, pitch, roll, yaw, and mode settings.2.4GHz TX and RX system is used for its better performance, because it will not experience signal conflicts from other radio frequency (RF) controllers. Receiver used is having 6C $2.4 \mathrm{Ghz}$ system which perfectly bonded with the 2.4Ghz transmitter.

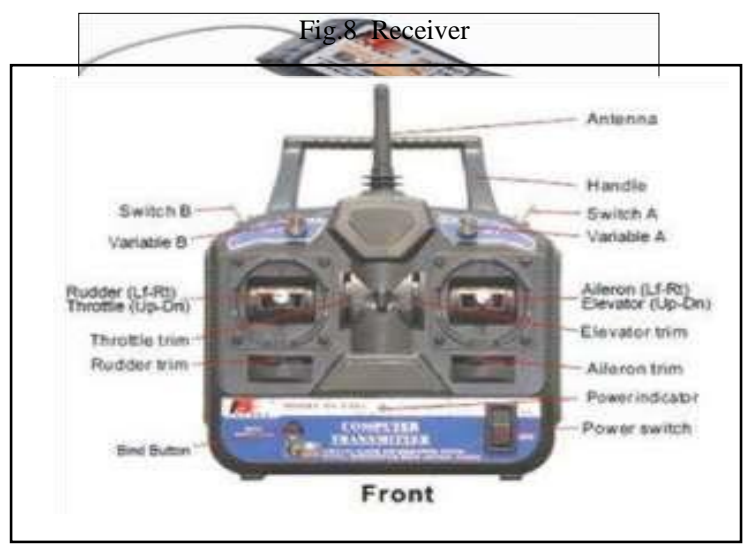

Fig.9. FLYSKY CT6B Remote

\section{Quadcopter frame}

The frame of quadcopter can be made from aluminium, carbon fibre or balsa wood. The comparison among various Properties of these materials are listed below-

\begin{tabular}{|c|c|c|c|}
\hline Property & $\begin{array}{c}\text { Aluminium } \\
(\mathbf{6 0 6 1})\end{array}$ & $\begin{array}{c}\text { Carbon } \\
\text { Fibre }\end{array}$ & $\begin{array}{c}\text { Balsa } \\
\text { wood }\end{array}$ \\
\hline $\begin{array}{c}\text { Young's } \\
\text { modulus(gpa) }\end{array}$ & 70 & 70 & 3 \\
\hline Poisson's ratio & 0.33 & 0.1 & 0.229 \\
\hline $\begin{array}{c}\text { Ultimate tensile } \\
\text { strength(mpa) }\end{array}$ & 550 & 600 & 14 \\
\hline $\begin{array}{c}\text { Ultimate } \\
\text { compressive } \\
\text { strength(mpa) }\end{array}$ & 469 & 570 & 7 \\
\hline $\begin{array}{c}\text { Density(gram/cc) } \\
\text { (gense }\end{array}$ & 2.86 & 1.6 & 0.13 \\
\hline
\end{tabular}


Aluminium (6061) is light and strong material, which dissipates heat well, and is relatively inexpensive compared to the other available options. Having Malleability, or the ability to be shaped. No sparking, so it's ideal for use near flammable substances. Resistant to corrosion, this makes it ideal for use outdoors. Nonmagnetic, hence it is not affected by electromagnetic forces. Thus Aluminium is a material which is used for arms and the centre plate. The cad assembly model for quadcopter is shown in following fig. The Aluminium frame of the vehicle is subjected to following analysis-

1. Static structural analysis

2. Modal analysis

3. Harmonic analysis

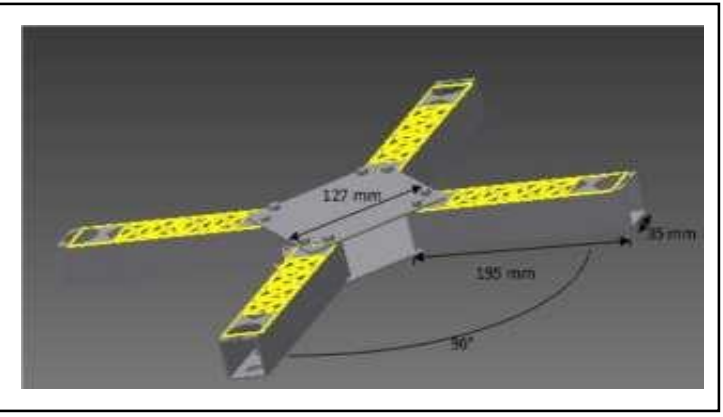

Fig.10. 3D CAD model of quadcopter frame

\section{Static structural analysis}

The boundary conditions for static structural analysis are shown in following fig.

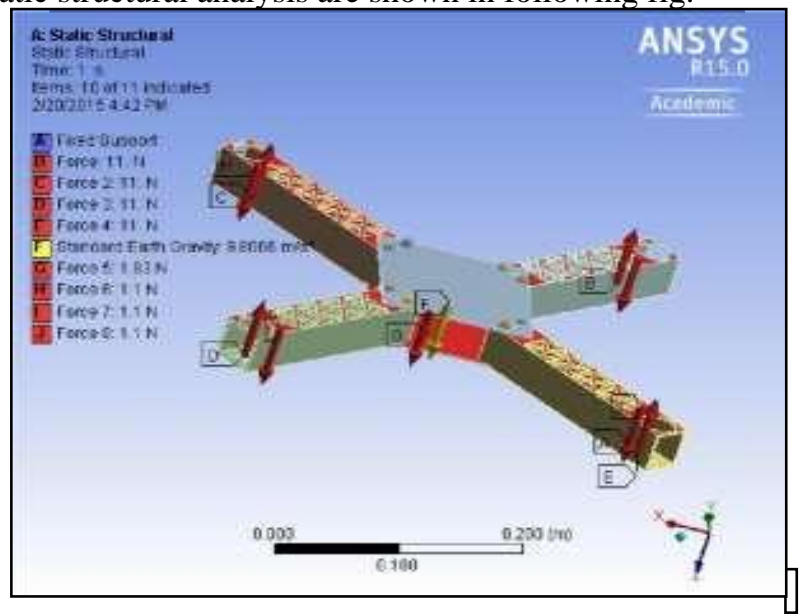

Fig.11.Application of boundary conditions

During application of boundary conditions, Thrust forces, gravitational force, downward force due to motor assembly are considered.Results:

\section{a. Deformation result}

\begin{tabular}{|c|c|}
\hline Minimum & $0 . \mathrm{m}$ \\
\hline Maximum & $1.3176 \mathrm{e}-006 \mathrm{~m}$ \\
\hline
\end{tabular}

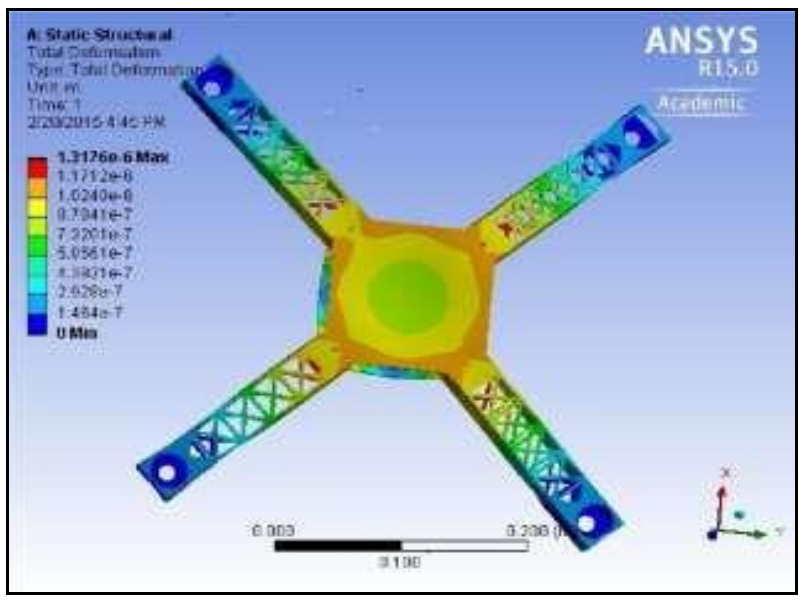

Fig.12.Total deformation analysis 


\section{b. Von mises Stress results}

\begin{tabular}{|c|c|}
\hline Minimum & $1.9369 \mathrm{~Pa}$ \\
\hline Maximum & $\begin{array}{c}7.5418 \mathrm{e}+005 \\
\mathrm{~Pa}\end{array}$ \\
\hline
\end{tabular}

Fig.14.Total deformation analysis

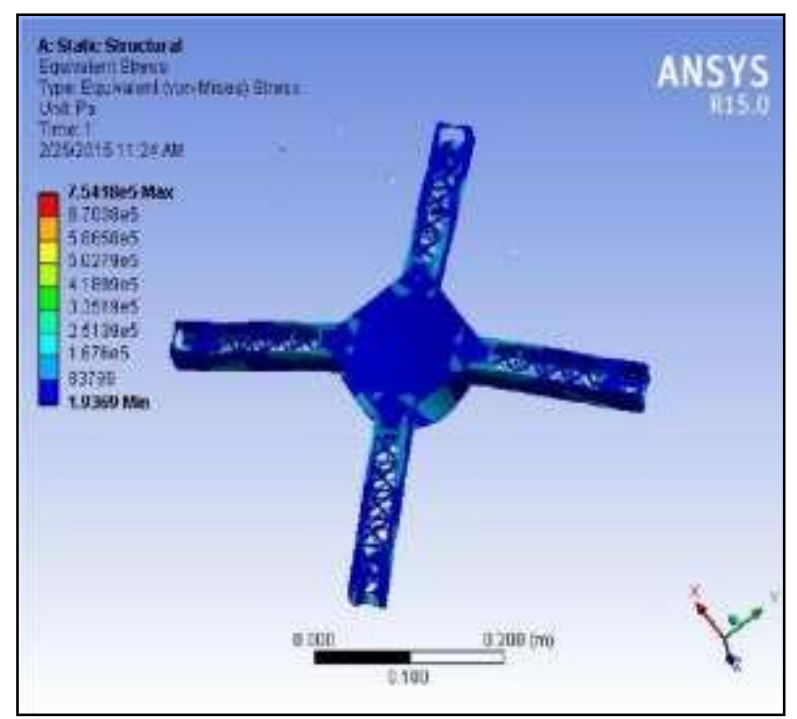

Fig.13. Von mises stress analysis

\section{Modal analysis}

This analysis is required to find the natural frequency of the frame. The frequency values are determined for different modes.

\begin{tabular}{|c|c|c|}
\hline Sr. no. & Modes & $\begin{array}{c}\text { Frequency } \\
(\mathrm{Hz})\end{array}$ \\
\hline 1. & Mode1 & 0 \\
\hline 2. & Mode2 & 0 \\
\hline 3. & Mode3 & $5.6555 \mathrm{e}-003$ \\
\hline 4 & Mode4 & 93.998 \\
\hline 5 & Mode5 & 98.038 \\
\hline 6 & Mode6 & 105.88 \\
\hline 7 & Mode7 & 295.51 \\
\hline 8 & Mode8 & 427.55 \\
\hline 9 & Mode9 & 439.28 \\
\hline 10 & Mode10 & 637.12 \\
\hline
\end{tabular}

\section{Harmonic analysis}

The results for harmonic analysis are displayed in terms of stress and deformation amplitudes.

\begin{tabular}{|l|r|r|}
\hline & Amplitude $(\mathrm{Pa})$ & Phase angle \\
\hline 100 & 11181 & 0 \\
\hline 200 & 11781 & 0 \\
\hline 300 & 12988 & 0 \\
\hline
\end{tabular}




\section{a. Stress amplitudes:}

\begin{tabular}{|l|r|r|}
\hline 400 & 15367 & 0 \\
\hline 500 & 21204 & 0 \\
\hline 600 & 73111 & 0 \\
\hline 700 & 1147.7 & 180 \\
\hline 800 & 17708 & 0 \\
\hline 900 & $1.27 \mathrm{E}+05$ & 0 \\
\hline 1000 & 29112 & 180 \\
\hline
\end{tabular}

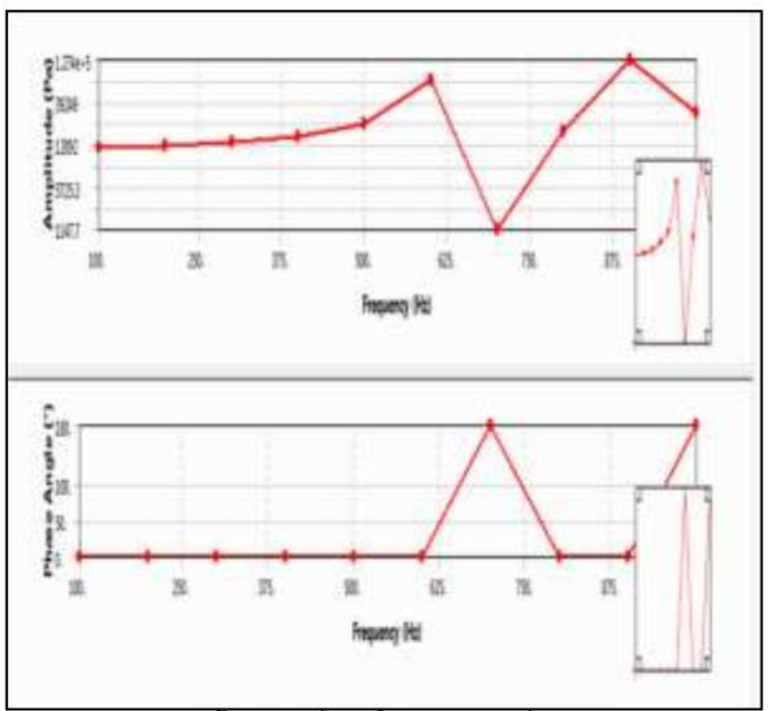

b. Deformation amplitudes:

\begin{tabular}{|c|c|c|}
\hline Frequency & Amplitude(m) & $\begin{array}{c}\text { Phase } \\
\text { angle }\end{array}$ \\
\hline 100 & $5.09 \mathrm{E}-10$ & 180 \\
\hline 200 & $7.31 \mathrm{E}-10$ & 180 \\
\hline 300 & $1.52 \mathrm{E}-09$ & 180 \\
\hline 400 & $1.18 \mathrm{E}-08$ & 180 \\
\hline 500 & $5.62 \mathrm{E}-09$ & 0 \\
\hline 600 & $1.53 \mathrm{E}-08$ & 0 \\
\hline 700 & $3.71 \mathrm{E}-09$ & 180 \\
\hline 800 & $2.64 \mathrm{E}-09$ & 180 \\
\hline 900 & $1.32 \mathrm{E}-08$ & 180 \\
\hline 1000 & $3.75 \mathrm{E}-09$ & 0 \\
\hline
\end{tabular}

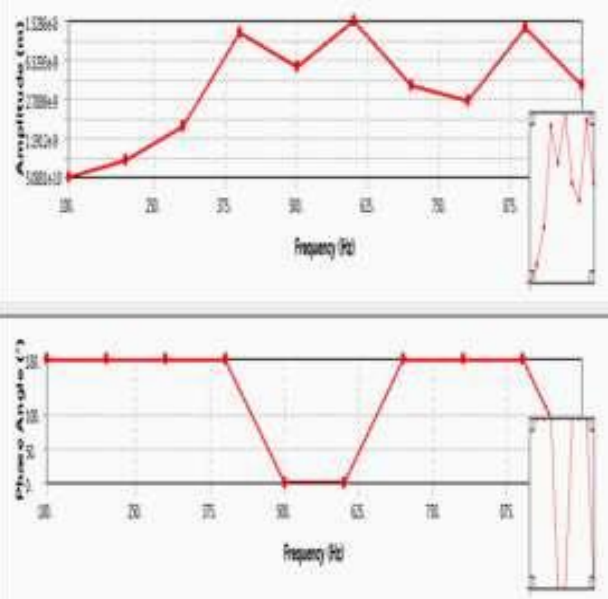

Fig.15. Frequency vs deformation amplitudes, Frequency vs phase angle

\section{Results and discussions}

By the studying design of quadcopter and its material for each part, final assembly of quadcopter is prepared in CAD model. Three kinds of analysis is carried out on quadcopter assembly.

First is static structural analysis, results shows that the deformation in model is minimum $0 \mathrm{~m}$ and maximum is $1.317 \mathrm{e} 006$ $\mathrm{m}$. the deformation is acceptable. Von mises stress result is minimum $1.9369 \mathrm{~Pa}$ and Coming on model are within the limit and model is safe.Second is modal analysis, this analysis is required for finding out the natural frequencies fordifferent modes. Ten modes are considered for getting frequency results. Min $0 \mathrm{~Hz}$ and maximum $637.12 \mathrm{~Hz}$ natural frequency showed in ansys result using modal analysis.

Third is Harmonic analysis, results in term of harmonic response are recorded and these are Stress amplitude(Pa) and Deformation amplitude (m). 


\section{Conclusion}

By applying the amount of thrust required during different maneuvers of quadcopter, gravitational force, self-weight of components attached to frame, deformation, stress, natural frequency results and harmonic response is studied using Ansys 15.0. The deformation and stress results for different types of analysis are within limit. So it is concluded that the design for quadcopter is safe.

\section{References}

[1] Parth. N. Patel, Journal of Advance in Electronic and Electric Engineering. ISSN 2231-1297, volume 3, Number4 (2013)

[2] Bernard Tat meng Leong et al, Journal of International Symposium on Robotics and intelligent sensors 2012(IRIS2012)

[3] Corey Russel et al, Journal of Design and Realization of intelligent portable Aerial surveillance system 43, pp.19231930 (2010)

[4] Hardik Modh "Quadrotor-An Unmanned Aerial Vehicle" in journal IJEDR Volume 2, Issue 1 pp. 1299-1303 in 2014

[5] P. Pounds and R. Mahony, "Design principles of large quadrotors for practical applications" in Proceedings of the IEEE International Conference on Robotics and Automation (ICRA), pp. 3265 -3270, May 2009 